\section{FICHA DE LA WEB}

\begin{tabular}{|l|l|}
\hline $\begin{array}{l}\text { URL PRINCIPAL DEL INSTITUTO } \\
\text { GETTY PARA LA INVESTIGACIÓN }\end{array}$ & http://www.getty.edu \\
\hline URL ÍNDICE DE TESAUROS & http://www.getty.edu/gateway/index/thesauri.htm \\
\hline URL AAT & http://shiva.pub.getty.edu/aat_browser/ \\
\hline TITULAR & Instituto Getty para la Investigación \\
\hline INFORMACIÓN DISPONIBLE & Muy Buena \\
\hline CALIDAD GRÁFICA & Regular \\
\hline FACILIDAD DE NAVEGACIÓN & Buena \\
\hline VELOCIDAD DE CARGA & Buena \\
\hline ACTUALIZACIÓN & Muy Buena: Última actualización 4/4/00 \\
\hline CALIFICACIÓN GLOBAL & Buena \\
\hline
\end{tabular}

\section{Bibliografía}

BARROSO RUIZ, Ma Soledad: "La normalización terminológica en los museos. El tesauro", en Revista General de Información y Documentación, vol. 2, n4. Madrid: Editorial Complutense, 1994. pp. 143 - 145.

Susana Limón Rodríguez Centro de Documentación del IAPH

\title{
Las Jornadas Europeas sobre Acceso Multimedia al Patrimonio Cultural en CD-ROM
}

La Universidad Complutense de Madrid ha editado el CD-ROM que contiene las actas de las I Jornadas Europeas sobre Educación y Tecnologías en la Sociedad de la Información, denominadas "El Acceso Multimedia al Patrimonio Cultural" y celebradas del 19 al 21 de noviembre de 1998.

Las Jornadas se desarrollan en el marco de la Iniciativa MEDICl de la Comisión Europea, y en ellas colaboran diversas instituciones como la Comunidad de Madrid, la Comisión Interministerial de Ciencia y Tecnología, el Programa INFO2000, Hispania Nostra, etc.

La Iniciativa MEDICl es una "Estructura de cooperación" establecida y supervisada por la DG XIII en conjunción con la DG $X$, que defiende el uso innovador de la tecnología multimedia para facilitar el acceso y la explotación efectiva del patrimonio cultural europeo. $\mathrm{MEDICl}$ está abierta a todo tipo de organismos e instituciones, públicos y privados, que compartan esta meta.

Las I Jornadas Europeas se celebraron en la Facultad de Ciencias de la Información de la Universidad Complutense, aunque también cedieron sus salones de actos el Museo Nacional Centro de Arte Reina Sofía y la Biblioteca Nacio- nal. La dirección del encuentro corrió a cargo de Arturo Colorado, Profesor Titular de Teoría e Historia del Arte de la Universidad Complutense de Madrid, y de André Jean-Marc Loechel, Presidente de Arenotech (Association Européenne Art-Éducation-Nouvelles Technologies).

El objetivo principal del encuentro es el análisis y la difusión del fenómeno cultural europeo a través de la tecnología hipermedia y la enseñanza y divulgación del patrimonio cultural basándose en los principios de la interactividad y en las creaciones de la realidad virtual con contenidos culturales. Concretamente, en este ámbito se afrontan tres retos fundamentales:

- La apropiación de las imágenes por parte de los ciudadanos.

- La convergencia digital.

- La creación de un seminario temático europeo.

Estas jornadas van destinadas a todos los profesionales relacionados con el ámbito de la cultura y la educación e interesados en las aplicaciones pedagógicas y de difusión de las tecnologías de la información, principalmente conservadores y miembros de los gabinetes de educación de los museos, gestores del patrimonio cultural, profesionales del patrimonio histórico-artístico, etc.
El CD-ROM se inicia de forma automática con una serie de fotografías de bienes históricoartísticos que forman parte del Patrimonio Cultural europeo. A continuación aparece el menú principal, a partir del cual se puede navegar por la presentación y justificación de las jornadas, las conferencias y las experiencias, con texto e imágenes de las mismas, las mesas redondas, las visitas organizadas y las conclusiones.

Las conferencias, que se agrupan en torno al título "Educación y acceso multimedia al patrimonio cultural", están dedicadas a temas como el proyecto MÉDICl, la difusión de información sobre patrimonio cultural, el tratamiento de la riqueza cultural desde una perspectiva pedagógica, o la puesta en valor de los bienes culturales, entre otros.

Desde el listado con los títulos de las conferencias y los nombres de los ponentes es posible acceder a los contenidos de cada una de las charlas, en unos casos los habituales textos y en otros integrados por conexiones a direcciones de Internet, que se pueden activar directamente desde el CD con sólo tener abierto un navegador. Junto a los textos aparece un icono que nos permite realizar un recorrido por imágenes fotográficas relacionadas con la conferencia. 
Las experiencias, también centradas en el tema de la cultura y la educación en el ámbito de las tecnologías multimedia, giran en torno a temas como las nuevas tecnologías en documentación e información aplicadas al estudio del patrimonio cultural, el acceso a través de Internet a museos, bibliotecas $y$, en general, a las instituciones relacionadas con el patrimonio, etc.

A continuación, siempre volviendo al menú principal, podemos utilizar el ratón para obtener información sobre las mesas redondas que se desarrollaron a lo largo del encuentro. En éstas se pueden encontrar propuestas acerca de la gestión creativa de actividades que tengan por objeto la difusión del patrimonio cultural en la sociedad de la información y de proyectos que aborden la presencia de museos e instituciones culturales en el ámbito multimedia.

Asimismo, se hace referencia a los principales desafíos de la era digital en relación al patrimonio cultural: el libre acceso a las imágenes y la cultura por parte de los ciudadanos y la introducción de las nuevas tecnologías digitales en los diferentes sistemas educativos.

Por otro lado, el CD-ROM también presta atención a las visitas organizadas que se lleva-

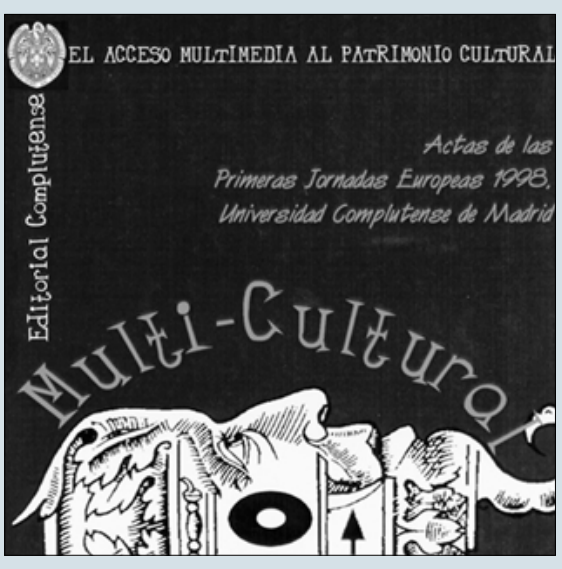

ron a cabo durante la celebración de las Jornadas al Museo Nacional Centro de Arte Reina Sofía, al Museo Interactivo del Libro y al Museo Internacional de Electrografía de Cuenca. En algunos casos, el CD permite realizar un recorrido virtual por estas instituciones a través de imágenes tanto de las dependencias como de sus fondos.

En último lugar, encontramos un apartado dedicado a las conclusiones del encuentro. En ellas se destaca la nueva concepción, más amplia que la tradicional, del patrimonio cultural, de su valor de uso irremplazable y de la necesidad de integrar este patrimonio en la vida cotidiana.

Esta nueva concepción puede encontrar en la tecnología hipermedia una vía de desarrollo de alcance insospechado, que permitirá difundir una visión amplia, científica y amena de la cultura, aprovechando el abanico de posibilidades que ofrece la interactividad de acercar al usuario a la comprensión y el disfrute del patrimonio.

\section{Mención de responsabilidad}

Dirección: Arturo Colorado Castellary

Dpto. de Comunicación Audiovisual y Publicidad II Universidad Complutense. Madrid

Diseño gráfico, fotografias y programación en lingo: Eva $M^{a}$ de la Torre Ruiz

Edición: Editorial Complutense

I.S.B.N. 84-89784-90-8

\section{Requerimientos técnicos recomendados}

- Windows 95

- Pentium 133 Mhz

- RAM 24 Mb

- Display Millones de colores (24 bits)

- CD-ROM 20x

- Tarjeta de sonido

María Victoria Madrid Díaz Centro de Documentación, IAPH

\section{Información Bibliográfica sobre Tesauros de Patrimonio Histórico}

En la selección bibliográfica que presentamos se recogen aquellos Tesauros, publicaciones y herramientas afines que por su contenido, se encuentran relacionados de forma global o parcial, con algunas de las disciplinas que integran el Patrimonio Histórico. En algunos casos su temática induce a pensar, a simple vista, que su relación con el Patrimonio Histórico es nulo, pero al introducirnos en el corpus interno encontramos una serie de desciptores relativos a distintas parcelas del conocimiento que se pueden aplicar al Patrimonio Histórico. Esta selección la acompañamos de monografías y artículos que tratan sobre el Tesauro de Patrimonio Histórico Andaluz, bibliografía no muy extensa pero que muestra el pasado, presente y futuro del lenguaje documental del Sistema de Información del Patrimonio Histórico Andaluz (SIPHA).
ART and Architecture Thesaurus. New York: Oxford University Press, 1994. (Published on behalf of the Getty Art History Information Program).

ASIS thesaurus of information science and librarianship. Medford (New Jersey): Published for the American Society for Information Science, 1994.

The BRITISH Museum materials thesaurus. Cambridge: MDA in association with the British Museum, 1997.

BULLETIN of the vocabulary program. Los Angeles: Getty Information Institute, c.1997. Semiannual. N N I (1997)-

CENTRO de Estudios y Experimentación de Obras Públicas. Tesauro de puertos y costas. [Madrid]: CINDOC, 1996.
DOMENECH FERNÁNDEZ, Silvia. Tesauro BIMA. Barcelona: Archivo Municipal, 1997.

FERREZ, Helena Dodd; BIANCHINI, Maria Helena $S$. Thesaurus para acervos museológicos. Rio de Janeiro: Fundaçao Nacional Pró-Memória, 1987. (Série Técnica, I)

FINDEX: facet-oriented indexing system for architecture and construction engineering... Sttutgart: Irb-Verlag, 1985.

GARNIER, François. Thesaures iconographique: système descriptif des représentations. Paris: Le Léopard d'or, D.L. 1984.

GIL LABLANCA, Rafael. Tesauro de Obras Hidraúlicas. Madrid: CINDOC, 1996. 